\title{
LAS BASES DE DATOS CIEN AÑOS DESPUÉS DEL DESASTRE COLONIAL
}

\section{DATABASES HUNDRED YEARS AFTER THE DISASTER COLONIAL}

\section{AUTORA}

\section{María Victoria Nuño Moral}

Dpto. de Biblioteconomía y Documentación. Facultad de Ciencias de la Información. Universidad Complutense de Madrid. (España)

marivinm@eucmax.sim.ucm.es

\section{RESUMEN}

Con el transcurrir de la Historia, es necesaria la posesión de bases de datos y archivadores en los cuales poder almacenar la información y documentación que el transcurso de los años va generando, para poder -si es necesario- ser utilizada en un futuro. El artículo explica cómo se originaron los primeros archivadores, en qué momento de la Historia aparecieron y, desde entonces, cómo han evolucionado y cómo se ha ido archivando la Historia. EI CD-ROM es, actualmente, el medio que posee la más elevada capacidad de almacenamiento.

\section{PALABRAS CLAVE}

Historia - Documentación - Bases de datos - Posteridad - CD-ROM

\section{ABSTRACT}

With the passage of history, it is necessary to possession of databases and file in which to store the information and documentation that over the years is generating, so, if necessary, be used in the future. The article explains how to rise to the first filing, at what point in the story appears, and since then, how they evolved and how 
it has been filing history. The CD-ROM is currently the medium that has the highest storage capacity.

\section{KEY WORDS}

History - Documentation - Databases - Posters - CD-ROM

\section{ÍNDICE}

1. Introducción.

2. Ejemplos españoles en CD-ROM.

3. Bibliografía.

\section{Introducción.}

Para la Historia Contemporánea, los Centros de Documentación en Prensa son esenciales. Allí está la memoria más ecléctica y fiel, en buena parte de los casos, desde hace más de dos siglos. Por ello nos ha parecido oportuno dar un breve resumen de cómo se trabaja en los Centros de Documentación a la hora no sólo de almacenar y conservar la información, sino al recuperarla para el quehacer histórico o científico informativo.

Uno de los aspectos más importantes que hoy presenta cualquier información no es solamente que ésta exista sino que cuando precisamos de ella podemos disponer en mayor o menor medida de la misma. Para ello, el conjunto de noticias debe ser tratado, procesado y clasificado para su posterior utilización.

Desde un punto de vista general, al hablar de las tareas documentales podemos remontarnos a la segunda mitad del tercer milenio A. C., con el hallarzgo de los Archivos de Ebla donde se encontraron alrededor de 8.000 documentos y fragmentos 
textuales principalmente de carácter administrativo. Es considerado como el primer atisbo de Biblioteconomía y Documentación ya que los documentos -descubiertos en 1975- aparecen distribuidos de forma homogénea de acuerdo con los temas tratados: económico-comerciales, históricos y documentos léxicos.

Para comprender mejor la mecánica de trabajo que se desarrolla hoy, hemos de señalar de forma breve cuál ha sido la evolución de los Centros de Documentación Periodísticos. A la hora de enmarcar el origen de los mismos se alude fundamentalmente a tres hechos: la utilización de diferentes diarios para la elaboración de nuevas informaciones; el registro de ejemplares correspondientes a un mismo periódico y las informaciones necrológicas, sobre todo cuando empiezan a venir acompañadas de ilustraciones, lo que suponía un elevado coste y hace necesaria su conservación.

Surgen así los Archivos de Recortes que va a ser el primer método que constituye los fondos de archivos periodísticos. En ellos, la información empieza a estar localizada por personajes y posteriormente por temas, todo ello de forma manual. El semanario Neue Zürcher Zeitung será el pionero en desarrollar esta actividad junto con los diarios ingleses Times y Daily Mail. Todo esto empieza a combinarse con la elaboración de índices como hacia el diario New York Herald en 1860. En España, el diario La Vanguardia fue el primer periódico que dispone de Servicio Documental en los años 20.

Como se señala en innumerables ocasiones, el incremento de las informaciones y la superposición de datos origina problemas de espacio, gestión, y como consecuencia, de recuperación por lo que se produce el desarrollo de nuevos sistemas y soportes documentales.

El microfilm será el primer soporte que convive con el soporte papel, teniendo en cuenta que este último sigue ocupando el 85\% del material producido. En España, el uso de los soportes micrográficos se materializa por primera vez en los diarios $A B C$ y 


\section{El País.}

Se dará paso a la denominada tecnología COM (Computer Output Microfilm) que combinaba el ordenador con los sistemas micrográficos. Supone los primeros pasos de lo que posteriormente se denominó Bases de Datos. La primera base de datos periodística teledocumental la desarrolló el diario New York Times, en la cual se almacenaban resúmenes de noticias impresas. A partir de los años 70 , esta actividad se extiende por diferentes países hasta llegar a la comercialización de las mismas sobre todo con la aparición de las bases de datos de texto completo.

Hoy los soportes ópticos, y en especial el CD-ROM, juegan un papel muy importante en este ámbito dada la elevada capacidad de almacenamiento. En resumen, el desarrollo tecnológico sucedido en el presente siglo quedaría simplificado de la siguiente manera:

- Años 30: primer ordenador electrónico.

- Años 40-60: primeras búsquedas en línea.

- Años 60-70: Primeros ordenadores personales.

- Años 70-80: Regularización de las Memorias Ópticas.

- A partir de los años 80 se produce la llegada de la Red Internet. La entrada de la prensa en este mundo consuma una de las etapas de la Tecnología de la Información.

Por su parte, el origen de la Teledocumentación en España se sitúa en la década de los 70, de la mano del Instituto Nacional de Técnicas Aerospaciales (INTA) que instala el primer terminal de acceso a bases de datos remotas, lejanas al usuario. Este hecho se ve consolidado en 1979, tras ser creada dos años antes la Red INCa, destinada a la información científica automatizada. 
En la actualidad, la validez de un sistema de información depende de la calidad de la base de datos que lo soporta, ya que ésta se convierte en un elemento fundamental de dichos sistemas. Así, podemos afirmar que dichas bases de datos, en un medio de comunicación, cumplen una función de "memoria informativa" para cualquier profesional.

Podemos definir las bases de datos como un conjunto de datos, almacenados en soporte informático, que se estructuran y organizan con el fin de poder recuperarlos de diferentes y determinadas maneras. Encontramos fundamentalmente dos tipos: Referenciales que se convierten en fuente de información secundaria, y Factuales, consideradas como fuente de información primaria. Independientemente de la tipología, las bases de datos están formadas por los denominados registros (cada uno de los documentos que se almacenan) y cada registro estructurado en una serie de campos que en conjunto representan los datos físicos y de contenido de cada uno de esos materiales. Por tanto, se trata de un sistema que nos permite almacenar cualquier documento posible, objeto de recuperación.

Hoy, aparecen en el mercado bases de datos en soportes ópticos, a un precio moderado con las desventajas de la actualización, problema solventado, por otra parte, por la Teledocumentación en tareas correspondientes al archivo de documentos.

Los soportes ópticos y en especial el CD-ROM se ha convertido en el último sistema de almacenamiento lanzado al mercado por parte de los diferentes Centros de Documentación y en definitiva por parte de las diferentes empresas periodísticas. Con estos nuevos soportes se maximia el equilibrio entre la cantidad y la calidad de la información almacenada.

Estos han irrumpido en el mercado periodístico español en los últimos años. Nos centramos principalmente en tres diarios: El Mundo, La Vanguardia y El Periódico de Cataluña. Mención especial al CD-ROM editado por el diario $A B C-A B C$ Cultural - por 
ser pionero en la prensa española.

El CD-ROM es aceptado como soporte válido desde el punto de vista del almacenamiento masivo de informaciones independientemente de la naturaleza de las mismas. Dadas sus características técnicas se convierte en soporte auxiliar dentro del ámbito documental, aunque todavía no ha sido "explotado" suficientemente por parte de los profesionales, desde el punto de vista de la utilización.

El CD-ROM, tal y como lo han presentado los medios de comunicación, aparece como un sistema de almacenamiento y de difusión/distribución de la información con una finalidad principalmente comercial. Resulta insuficiente como instrumento de trabajo en un Centro de Documentación de Prensa, fundamentalmente por dos aspectos: se trata de un sistema cerrado, el cual no permite ningún tipo de manipulación una vez que la información ha sido grabada -aunque atendiendo al contenido, a un Centro de Documentación de Prensa le interesa tener almacenadas noticias tal y como aparecen en formato impreso-; y en segundo lugar, sería necesario cambiar su organización actual para mejorar las prestaciones y atender de forma más adecuada a las necesidades de cualquier usuario, principalmente de los propios periodistas.

En suma, podemos afirmar que estos nuevos productos se han editado como mero producto de almacenamiento que no de utilización masiva, con una finalidad más comercial que productiva.

\section{Ejemplos españoles en CD-ROM.}


Seguidamente vamos a exponer las características más relevantes de cada uno de los ejemplos españoles, empezando por los dos productos más afines como son el CD-ROM editado por el diario El Mundo y La Vanguardia respectivamente.

El diario El Mundo lanzó su primer CD-ROM con noticias almacenadas desde 1994 y en la actualidad se sigue editando. Se halla estructurado en tres bases de datos Noticias, Fotografías y Portadas- sin conexión entre ellas, en las que se almacenan documentos textuales y fotográficos. La base de datos de Portadas extá vacía de contenido, por lo que las búsquedas de este tipo de documentos hay que realizarla en la base de datos de Noticias.

Presenta un doble formato de visualización: electrónico e impreso para todas las noticias. Sólo visualizamos la información que demandamos y no las páginas completas. En el caso de las fotografías podemos visualizar varios documentos a un mismo tiempo.

Por su parte, la ventana de consulta está estructurada en tres bloques: Campos, Funciones y Ventana de Resultados. Los Campos vienen acompañados de ventanas de ayuda y algunos disponen de un listado de términos previamente establecidos por el documentalista.

En la base de datos de Noticias, de los once campos que la componen, cuatro son propiamente de contenido (Texto, Títulño, Lead y Cabecera). De todas las funciones existentes destaca "Histograma" y "Sugerencia temática".

La base de datos de Fotografías no incluye los gráficos y está formada por ocho campos, de los cuales tres están directamente relacionados con el contenido (Personajes, Descripción y Asunto).

La base de datos de Portadas, al estar vacía de contenido, las consultas se realizan en la base de datos de Noticias rellenando el campo Página. Sólo se visualiza la noticia concreta, no la Portada completa. 
En cuanto a los resultados, se muestran en la misma ventana de consulta, en la parte inferior de la misma. Existe una primera ventana donde aparece señalado el número de consulta, de documentos y ocurrencias encontradas, así como los comandos y términos utilizados. Activando la función correspondiente ("Servir Consulta") aparece la lista de referencias de dichos documentos de acuerdo con los siguientes parámetros: Fecha, Sección y Lead. En el caso de las fotografías podemos visualizar las referencias o los documentos directamente. La lista de referencias comprende los siguientes parámetros: Fecha, Personajes, Localización y Descripción.

El CD-ROM de La Vanguardia aparece también en 1994, aunque es en 1995 cuando editan un disco óptico que contiene fotografías y gráficos junto con las noticias impresas; el anterior sólo contenía el texto de las noticias. Al igual que el soporte anterior, tiene una periodicidad semestral y sólo se ha editado para PC dejando al margen a los usuarios de Macintosh.

Está estructurado en tres bases de datos -Noticias, Fotos/Gráficos y Portadas- que se encuentran interconectadas. En este caso, la base de datos de Portadas si contiene información.

También presenta un doble formato de visualización: electrónico y papel, pero a diferencia del anterior soporte, la visualización en formato impreso sólo es posible en el caso de las Portadas. Visualizamos la información que demandamos, a diferencia de las Portadas donde vemos la página completa.

La ventana de consulta está igualmente estructurada en los mismos tres bloques que El Mundo. Del mismo modo, los campos de búsqueda disponen de ventanas de ayuda y algunos de un listado de términos prefijado.

La base de datos de noticias dispone de siete campos, de los cuales sólo dos -Título y Texto- son propiamente de contenido. Dentro de las funciones destacan "Histórico" 


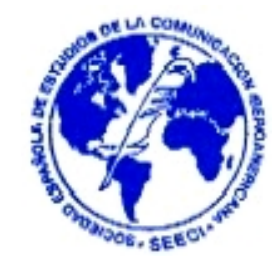

o "Recuperar consulta", inexistentes en el caso anterior.

La base de datos de Fotografías/Gráficos está formada por seis campos; sólo uno de ellos -Pie de Foto- está relacionado con el contenido.

Por último, la base de datos de Portadas está compuesta por un único campo de contenido: Texto. Como hemos señalado anteriormente, visualizamos la página completa en dos posibles modalidad: a escala o a tamaño natural.

En relación con los resultados, en el caso de las Noticias aparece una ventana en la que se indica el número de documentos encontrados $y$, aceptando dichos resultados se presenta el listado de referencias de acuerdo con los parámetros: Fecha, Ponderación, Valoración, Título y Vínculo con otra base de datos. Con los documentos Iconográficos, los parámetros son: Fecha, Ponderación, Pie de foto y Tipo de documento iconográfico encontrado (Fotografía o Gráfico). Por último, en relación con las Portadas, los resultados se reflejan con dos datos: Fecha y Título, con todos los titulares que componen dicha página.

Una última alusión a ambos soportes en relación a los Operadores que utilizan. La Vanguardia oferta mayores opciones respecto al otro soporte analizado, ya que encontramos más posibilidades en relación a los operadores lógicos, más opciones a la hora de delimitar la proximidad, o los denominados operadores diccionario, que englobarían los sinónimos o derivados, inexistentes en el caso del diario El Mundo.

Sin comparamos las características que acabamos de señalar con el CD-ROM que aporta El Periódico de Cataluña, las diferencias son abismales. En un principio, este soporte no presenta ningún tipo de estructuración, ya que la labor de almacenamiento se ha limitado a escanear ejemplares completos, en donde cualquier término es recuperable sin hacer ningún tipo de distinción entre los diferentes textos que aparecen en dichas páginas. Es decir, es recuperable tanto una noticia como cualquier anuncio publicitario, nombre perteneciente al Consejo de Redacción, etc. En definitiva, no se ha estructurado ni analizado el contenido registrado. 
No obstante, a pesar de este hecho sí que existe conexión y está establecida entre las noticias de Portada y el desarrollo que de las mismas se lleva a cabo en páginas interiores. Por otra parte, los documentos iconográficos tampoco están analizados; estos sólo son recuperables a través del texto que les acompaña, bien sea pie de foto $o$ texto de la noticia propiamente dicha.

En cuanto a los resultados, junto con el número de documentos encontrados respecto del total almacenado sólo aparece un dato que es la Fecha de Publicación; la lista de referencias está ordenada por fechas empezando por las informaciones más actuales. Hemos de señalar que las fichas de información que acompañan a los documentos están vacías de contenido; sólo contiene la fecha de publicación y modificación y es, la mayoría de las veces, la misma.

En este CD-ROM se ha hecho mayor hincapié en las oportunidades funcionales que el usuario puede desarrollar. Así, nos posibilita alternativas a la hora de la Visulización (Ver Página Actual; ver todas las páginas, ver sólo portadas), del Desplazamiento (Por un mismo ejemplar, pasando de la primera a la última página; sólo por los documentos encontrados en una consulta; por informaciones previamente visualizadas, etc. ).

\section{Bibliografía}

ESPINOSA, Blanca et Al. (1994): Tecnologías Documentales. Tecnidoc. Madrid.

FUENTES, Eulalia (1995) : Manual de Documentación Periodística . Síntesis. Madrid.

GARCÍA GUTIÉRREZ, A. ; LUCAS FERNÁNDEZ, R. (1987): Documentación automatizada de los medios informativos. Paraninfo. Madrid.

GARCÍ A MORENO, María Antonia: "Nacimiento y desarrollo de la teledocumentación en España (1973-1979)". En Documentación de las Ciencias de la Información. Número 17. 1994.

LÓPEZ YEPES, J. (1996): Manual de Información y Documentación. Paraninfo. Madrid. 